\title{
Estimation of base flow using flow-sediment relationships in the Chinese Loess Plateau
}

\author{
Mingguo Zheng * \\ Key Laboratory of Water Cycle and Related Land Surface Processes, Institute of Geographic Sciences \& Natural Resources Research, Chinese Academic of Sciences, Beijing 100101, China
}

\section{A R T I C L E I N F O}

\section{Article history:}

Received 8 October 2013

Received in revised form 10 October 2014

Accepted 19 October 2014

Available online 5 November 2014

\section{Keywords:}

Base flow separation

Runoff

Sediment yield

Loess Plateau

\begin{abstract}
A B S T R A C T
A common practice to separate base flow from surface flow is to partition the streamflow into the high-frequency and low-frequency components. Instead, this study attempted to partition the streamflow into the erosive and non-erosive components and used the latter as an estimation of base flow. Previous work (Zheng et al., 2012) has reported a linear runoff-sediment yield relationship at the watershed scale in the Chinese Loess Plateau. It was found that the intercept term of this linear relationship represents the non-erosive-flow component of streamflow. We test this hypothesis using the long-term data (1950s to 1980s) of eight tributaries in the middle Yellow River, which are intentionally selected to represent various land surface compositions in the middle Yellow River. The estimated long-term mean, annual and monthly base flows using the flow-sediment relationship are reasonably comparable with those derived from the Lyne and Hollick filter method, whether the watershed management for soil conservation was implemented or not. Moreover, our method is arguably more accurate than the filter method, which tends to overestimate base flow by including all delayed components, not just groundwater flows, as base flow. Thus, our method does not only provide a new way to obtain base flow, but also has the potential to provide validation data in assessing the performance of other base flow separation methods.
\end{abstract}

(c) 2014 Elsevier B.V. All rights reserved.

\section{Introduction}

Base flow is a streamflow component which is considered as the outflow of the groundwater feeding a river especially during rainless periods (Aksoy et al., 2009). Base flow time series are not only of great importance for water resource management, but also are helpful for hydrologists to understand the spatial and temporal variability of runoff processes in river basins (Aksoy et al., 2009; Furey and Gupta, 2001; Huyck et al., 2005; Santhi et al., 2007). Direct and continuous measurements of base flow throughout a basin are practically impossible (Furey and Gupta, 2001; Gonzales et al., 2009). The separation of base flow from surface flow has long been a concern in hydrology (Fang et al., 2011; Gonzales et al., 2009; Hall, 1968; Huyck et al., 2005; Tallaksen, 1995; Yan et al., 2013). There have been numerous base flow separation methods, which can be categorized into three groups: graphical methods, digital filtering and separation based on chemical composition (Spongber, 2000). Graphical methods and chemical mixing techniques are labor intensive, especially when applied for long time periods (Chapman, 1999; Huyck et al., 2005). The digital filtering technology is objective and reproducible and is well applicable to long time series of discharge though it does not have physical or hydrological bases (Arnold et al., 2000; Huyck et al., 2005).

\footnotetext{
* Tel.: +86 1064888151 ; fax: +8610 64851844

E-mail address: zhengmg.04b@igsnrr.ac.cn.
}

The digital filtering technology is currently most commonly used. The technology works on the observation that base flow reacts slowly to rainfall relative to surface flow. As a result, the "slow" or low-frequency component of streamflow can be interpreted to be base flow and the "fast" or high-frequency component of streamflow can be attributed to surface flow. Base flow is clear and non-erosive. In contrast, surface flow is sediment-laden and erosive. As a result, the base flow can be presumably associated with the non-erosive-flow component of streamflow, which forms the cornerstone of our method to estimate base flow.

The object of this study is to estimate base flow by partitioning the streamflow into components of erosive flow and non-erosive flow using the runoff-sediment yield relationship in the middle Yellow River basin of China. We first established the runoff-sediment yield relationships for eight tributaries of the middle Yellow River. Then, we estimated the amount of base flow using both the runoff-sediment yield relationship and a common filter method. Finally, we examined the discrepancy between the two methods.

\section{Study area and data}

The middle stream of the Yellow River passes through the Loess Plateau (Fig. 1), where a thick loess mantle $(>100 \mathrm{~m}$ ) forms the most spectacular landscape. As an eolian deposit, the loess is silty (0.005$0.05 \mathrm{~mm}$ ) in texture and loosely compact (Zheng et al., 2013). The 


\section{Nomenclature}

$B F I(\%)$ the ratio of base flow to total streamflow;

$\mathrm{SSY}_{\mathrm{a}}\left(\mathrm{t} \mathrm{km}^{-2}\right)$

specific sediment yield for a single year;

$h_{\mathrm{a}}(\mathrm{mm})$ runoff depth for a single year;

$S S Y_{\mathrm{m}}\left(\mathrm{t} \mathrm{km}^{-2}\right)$

specific sediment yield for a single month;

$h_{\mathrm{m}}(\mathrm{mm})$ runoff depth for a single month;

$\overline{q_{\mathrm{d}}}\left(\mathrm{m}^{3} \mathrm{~s}^{-1}\right)$

daily mean flow discharge;

$\overline{S D_{\mathrm{d}}}\left(\mathrm{kg} \mathrm{s}^{-1}\right)$

daily mean sediment discharge;

$\overline{q_{\mathrm{dB}}^{\prime}}\left(\mathrm{m}^{3} \mathrm{~s}^{-1}\right)$

daily mean base flow discharge estimated using the Lyne and Hollick filter method;

$\overline{h_{\mathrm{aB}}}$ and $\overline{h_{\mathrm{aB}}^{\prime}}\left(\mathrm{mm} \mathrm{a}^{-1}\right)$

the calculated mean annual base flow using the flow-sediment relationship and the Lyne and Hollick filter method, respectively; $h_{\mathrm{aB}}$ and $h_{\mathrm{aB}}{ }^{\prime}(\mathrm{mm})$

the calculated annual base flow using the flow-sediment relationship and the Lyne and Hollick filter method, respectively;

$Q_{\mathrm{mB}}$ and $Q_{\mathrm{mB}}{ }^{\prime}\left(10^{4} \mathrm{~m}^{3}\right)$

the calculated monthly base flow using the flow-sediment relationship and the Lyne and Hollick filter method, respectively.

climate is generally semi-arid and temperate with a mean average annual precipitation ranging from $400 \mathrm{~mm}$ in northwest to $600 \mathrm{~mm}$ in southeast (Liu et al., 1994). Vegetation cover is generally sparse. Soil
Table 1

Gauging stations in eight tributaries of the middle Yellow River.

\begin{tabular}{lllrlll}
\hline $\begin{array}{l}\text { Station } \\
\text { no. }\end{array}$ & River & $\begin{array}{l}\text { Gauging } \\
\text { station }\end{array}$ & $\begin{array}{l}\text { Area } \\
\left(\mathrm{km}^{2}\right)\end{array}$ & $\begin{array}{l}\text { Data } \\
\text { period }\end{array}$ & $\mathrm{n}^{\mathrm{b}}$ & $\begin{array}{l}\text { Surface } \\
\text { materials }\end{array}$ \\
\hline 41 & Huangfuchuan & Huangfu & 3199 & $1956-1989$ & 33 & $1+3$ \\
42 & Kuyehe & Wenjiachuan & 8645 & $1956-1989$ & 32 & $1+2+3$ \\
43 & Tuweihe & Gaojiachuan & 3253 & $1956-1989$ & 33 & $1+2$ \\
44 & Wudinghe & Chuankou & 29662 & $1975-1989$ & 15 & $1+2$ \\
45 & Wudinghe & Dingjiagou & 23422 & $1960-1989$ & 29 & $1+2$ \\
46 & Qingjianhe & Yanchuan & 3468 & $1956-1989$ & 32 & 1 \\
47 & Yanhe & Ganguyi & 5891 & $1956-1989$ & 33 & 1 \\
48 & Pianguanhe & Pianguan & 1915 & $1958-1989$ & 31 & $1+4$ \\
49 & Qiushuihe & Lingjiapin & 1873 & $1956-1989$ & 32 & $1+4$ \\
\hline
\end{tabular}

a The numbers correspond to those given in Fig. 1 .

b $n$ represents the number of recorded years.

c The given numbers represent land surface materials appearing upstream of the stations. " 1 " represents the loess, " 2 " represents the eolian sand (i.e. the MU US Sandy Land in Fig. 1), "3" represents the weathered bedrock (mainly sandstone and silty sandstone), and " 4 " represents the hard bedrock. The surface material " 3 " is widely exposed in upper parts of the northern rivers (e.g. \#41 and \#42). The surface material "4" generally corresponds to well-vegetated mountains (e.g. the Lvliang Mountain in Fig. 1).The surface materials 1-3 generally correspond to sparse vegetation coverage.

erosion is largely driven by localized short-duration, high-intensity convective rainstorms. A single rainstorm can commonly cause a soil loss over $10000 \mathrm{t} \mathrm{km}^{-2}$.

Data observed at nine gauging stations in eight tributaries of the middle Yellow River were used (Table 1). Besides loess, eolian sand and bedrock also appear in the middle Yellow River (Fig. 1). The eight rivers are intentionally selected to consist of various land surface compositions (see Table 1). The data used involves three time scales: annual specific sediment yield $\left(S S Y_{\mathrm{a}}, \mathrm{t} \mathrm{km}^{-2}\right)$ and annual runoff depth $\left(h_{\mathrm{a}}, \mathrm{mm}\right)$, monthly specific sediment yield $\left(S S Y_{\mathrm{m}}, \mathrm{t} \mathrm{km}^{-2}\right)$ and monthly

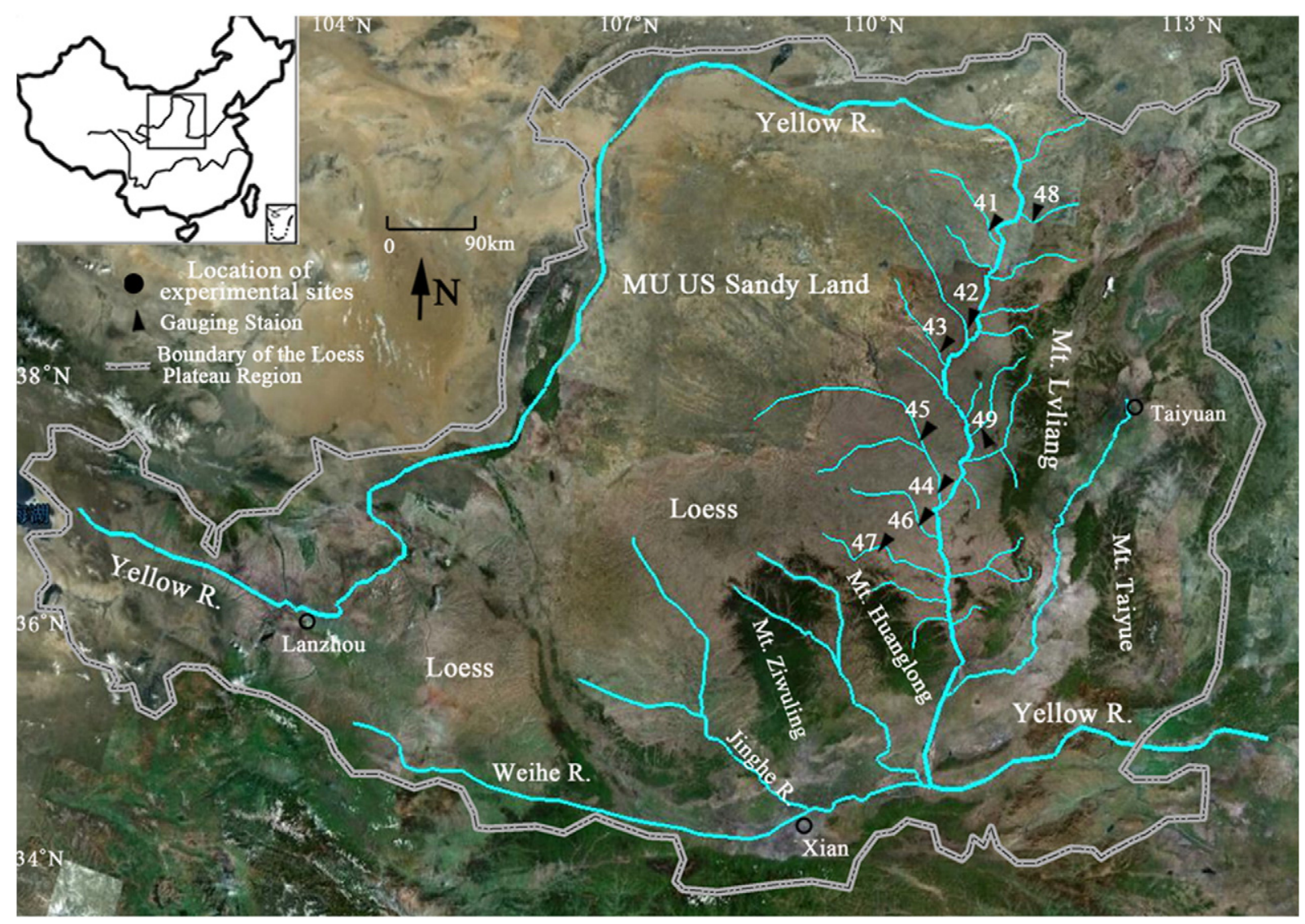

Fig. 1. Location of study areas. The numbers, corresponding to those used in Table 1, indicate the locations of the examined gauging stations The image was derived from the Google Earth. 
Table 2

Base flow estimations from the regression equation of $S S Y_{a}=b h_{a}+a$ and the comparison with those from the Lyne and Hollick filter method.

\begin{tabular}{lllrlllrr}
\hline Period & Station no. & $b$ & $-a$ & $R^{2}$ & $\begin{array}{c}\overline{h_{\mathrm{aB}}} \\
\left(\mathrm{mm} \mathrm{a}^{-1}\right)\end{array}$ & $\begin{array}{l}\overline{h_{\mathrm{aB}}^{\prime}} \\
\left(\mathrm{mm} \mathrm{a}^{-1}\right)\end{array}$ & $\begin{array}{l}D^{\mathrm{a}} \\
(\%)\end{array}$ \\
\hline Before 1970 & 41 & 409 & 5179 & 0.89 & 12.7 & 20.0 & -37 \\
& 42 & 285 & 10019 & 0.75 & 35.3 & 44.5 & -21 \\
& 43 & 298 & 30056 & 0.63 & 101.2 & 102.0 & -1 \\
& 45 & 161 & 4810 & 0.37 & 29.9 & 38.2 & -22 \\
& 46 & 512 & 9162 & 0.92 & 17.9 & 18.6 & -4 \\
& 47 & 444 & 7700 & 0.9 & 17.3 & 19.1 & -9 \\
& 48 & 565 & 8997 & 0.96 & 15.9 & 16.8 & -5 \\
& 49 & 342 & 5180 & 0.9 & 15.2 & 25.6 & -41 \\
& 41 & 377 & 1477 & 0.87 & 3.9 & 13.9 & -72 \\
& 42 & 292 & 9044 & 0.71 & 31.0 & 36.9 & -16 \\
& 43 & 235 & 19720 & 0.55 & 83.9 & 81.1 & 3 \\
& 44 & 345 & 10232 & 0.86 & 29.7 & 26.9 & 10 \\
& 45 & 140 & 3881 & 0.5 & 27.7 & 26.8 & 3 \\
& 46 & 461 & 9610 & 0.85 & 20.8 & 21.0 & -1 \\
& 47 & 427 & 8532 & 0.78 & 20.0 & 18.8 & 6 \\
& 48 & 501 & 2409 & 0.9 & 4.8 & 6.1 & -21 \\
& 49 & 283 & 2238 & 0.8 & 7.9 & 13.4 & -41 \\
\hline
\end{tabular}

a $\overline{h_{\mathrm{aB}}}=-a / b$ represents the calculated mean annual amount of base flow using the established $h_{\mathrm{a}}-S S Y_{\mathrm{a}}$ relationships. $\overline{h_{\mathrm{aB}}^{\prime}}$ represents the calculated mean annual amount of base flow using the Lyne and Hollick filter method. $D=\left(\overline{h_{\mathrm{aB}}}-\overline{h_{\mathrm{aB}}^{\prime}}\right) / \overline{h_{\mathrm{aB}}^{\prime}}$, representing the calculation discrepancy between the two methods.

runoff depth $\left(h_{\mathrm{m}}, \mathrm{mm}\right)$, and daily mean flow $\left(\overline{q_{\mathrm{d}}}, \mathrm{m}^{3} \mathrm{~s}^{-1}\right)$ and sediment $\left(\overline{S D_{\mathrm{d}}}, \mathrm{kg} \mathrm{s}^{-1}\right)$ discharges. Before 1970, the loess Plateau was under intensive agriculture use with limited soil conservation practices. After 1970 , soil conservation work was extensively undertaken. For this reason, we individually made base flow calculations for periods before and after 1970.

Observations of all experimental sites were made by stream-gauging crews of the Yellow River Water Conservancy Commission. For details of the measurement procedures, see Yan (1984) and Sedimentation Commission of Chinese Society of Hydraulic Engineering (1992). More information about the Loess Plateau and the field monitoring programs is available in Zheng et al. (2011, 2012, 2013).
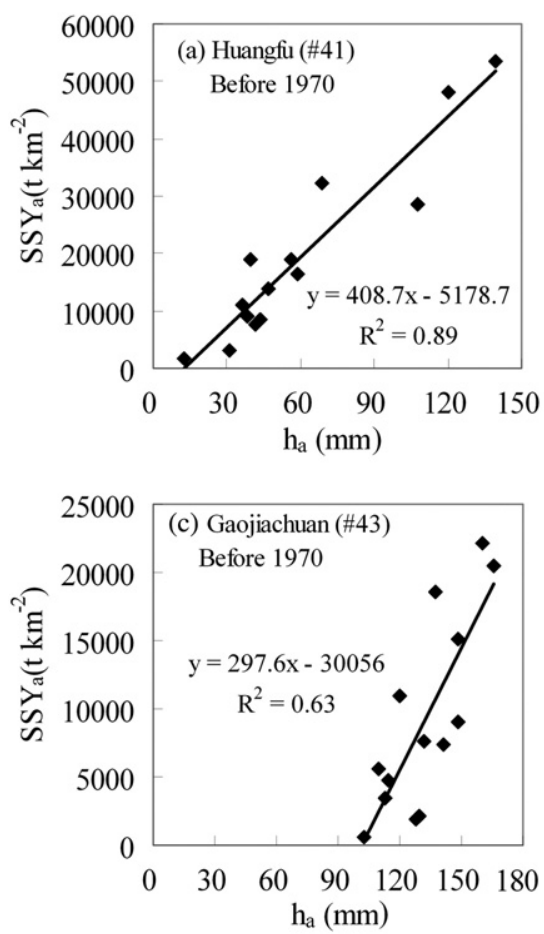

\section{Methodology}

Zheng et al. (2008, 2012) found that the runoff-sediment yield relationship of single runoff events can be perfectly fitted $\left(R^{2}>0.9\right)$ using a proportional function over a wide range of spatial scales in the Loess Plateau. This proportional relationship, however, is physically linear with a negligible constant term due to the presence of base flow at the watershed scale (Zheng et al., 2012). Responding to higher proportion of base flow at the annual timescale, the constant term is large enough such that the $h_{\mathrm{a}}-S S Y_{\mathrm{a}}$ relationship becomes linear with a nonzero intercept (Zheng et al., 2012). The linear regression equation of $S S Y_{\mathrm{a}}=b h_{\mathrm{a}}+a$ can be rewritten as:

$\operatorname{SSY}_{a}=b\left(h_{a}-(-a / b)\right)$,

where $b$ and $a$ are the slope term and the constant term, respectively. Mathematically, $-a / b$ is the $x$-intercept. It should be noted that $-a / b$ always has the same unit as $h_{\mathrm{a}}$. Sediment yield occurs unless $h_{\mathrm{a}}>-a / b$. Since any sediment-laden flow must exceed the base flow discharge, $\overline{h_{\mathrm{aB}}}=-a / b$ can be considered as an estimation of the mean amount of base flow over the examined period $\left(\mathrm{mm} \mathrm{a}^{-1}\right)$. The term $\left(h_{\mathrm{a}}-(-a / b)\right)$ can be interpreted to be the erosive-flow component of streamflow, i.e. surface flow, and the term $b$ can be interpreted to be the mean sediment concentration of surface flow. $\overline{h_{\mathrm{aB}}}$ thus corresponds to the non-erosive-flow component of streamflow.

\section{Results and discussion}

The $h_{\mathrm{a}}-S S Y_{\mathrm{a}}$ relationships are well fitted using a linear function in terms of $R^{2}$ for most rivers under examination, whether for the pre or the post 1970 period (Table 2). Fig. 2 illustrates the $h_{\mathrm{a}}-S S Y_{\mathrm{a}}$ relationships at stations of Huangpu (\#41) and Gaojiachuan (\#43). Table 2 gives the mean annual amount of base flow, $\overline{h_{\mathrm{aB}}}$, estimated from $-a / b$, for all examined stations. The resultant values of $\overline{h_{\mathrm{aB}}}$ lie between 12.7 and $101.2 \mathrm{~mm} \mathrm{a}^{-1}$ before 1970 , and between 3.9 and $83.9 \mathrm{~mm} \mathrm{a}^{-1}$ after 1970.
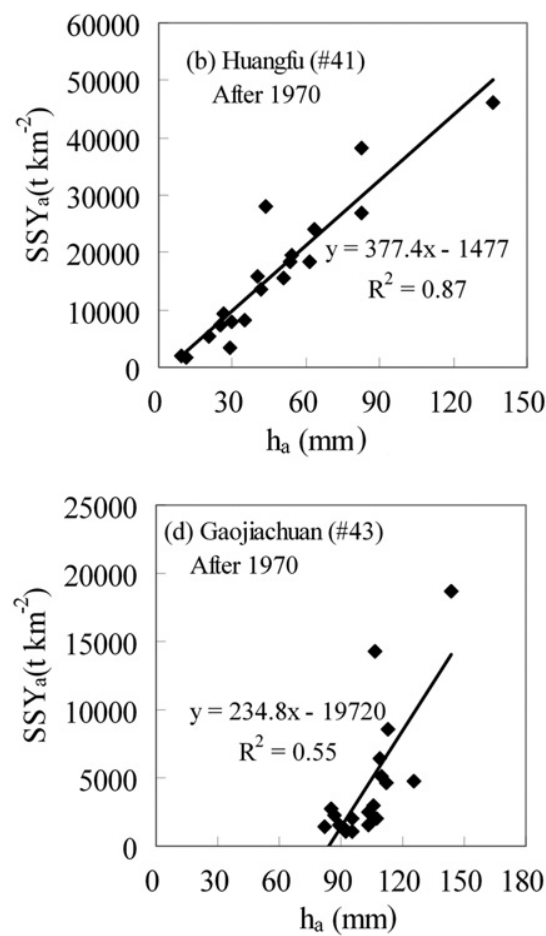

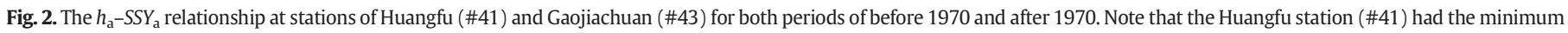
$x$-intercept (i.e. $\overline{h_{\mathrm{aB}}}$ in Table 2) and the Gaojiachuan station (\#43) had the maximum $x$-intercept among the examined stations. 

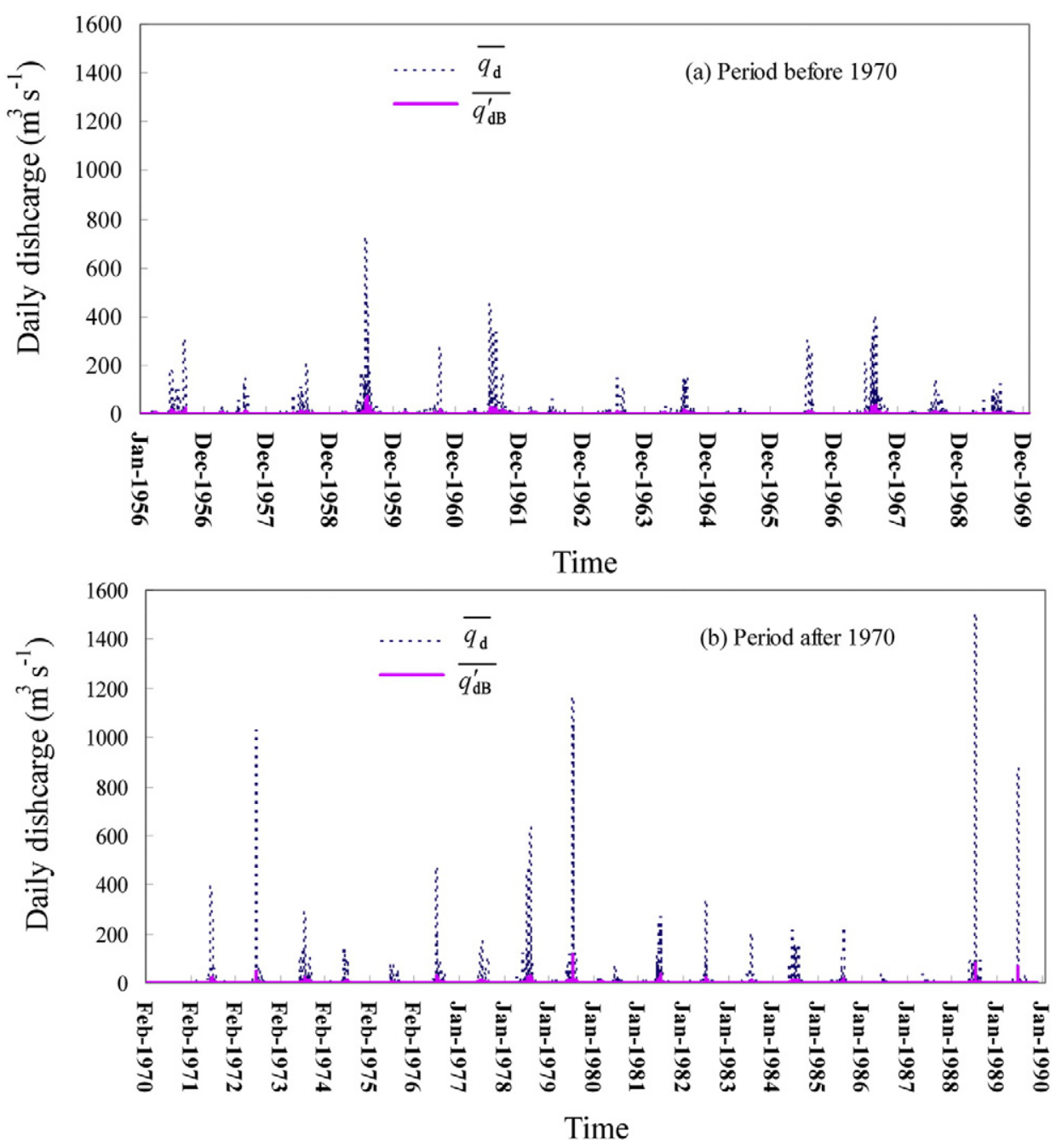

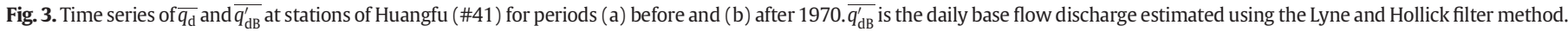

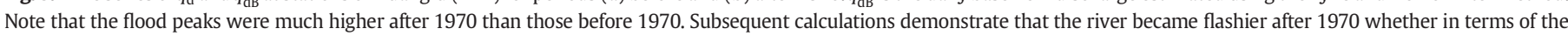
variation coefficient of $\overline{q_{\mathrm{d}}}$, the ratio of $\overline{q_{\mathrm{d}}}$ corresponding to $5 \%$ frequency of exceedance to the median $\overline{q_{\mathrm{d}}}$, or the ratio of base flow to total streamflow.

To validate our method, we obtain the base flow hydrographs from the $\overline{q_{\mathrm{d}}}$ time series using the Lyne and Hollick filter method (Nathan and McMahon, 1990), which appears to be most widely found in literature. The filter parameter was conventionally set at 0.925 . Dou and Huang (2010) calculated the base flow indices (BFI, the ratio of base flow to total streamflow) for six rivers of the Loess Plateau with various methods, arguing that the Lyne and Hollick filter method performs best. The resultant mean annual amount of base flow, $\overline{h_{\mathrm{aB}}^{\prime}}\left(\mathrm{mm} \mathrm{a}^{-1}\right)$, was given in Table 2. Fig. 3 shows the separated hydrographs for the Huangfu station (\#41).

For the period before 1970, the relative difference between $\overline{h_{\mathrm{aB}}}$ and $\overline{h_{\mathrm{aB}}^{\prime}}$ averages $17.4 \%$. For the period after 1970, the relative difference averages $19.3 \%$. The good consistency between $\overline{h_{\mathrm{aB}}}$ and $\overline{h_{\mathrm{aB}}^{\prime}}$, as demonstrated in Fig. 4, corroborates the validity of our derived $h_{\mathrm{aB}}$.

$\overline{h_{\mathrm{aB}}}$ should be more accurate than $\overline{h_{\mathrm{aB}}^{\prime}}$. The Huangfuchuan river watershed (\#41), where zero flow on average occurred on as many as 72 days per year over the period from 1959 to 1986 (Jiao, 1993), is among the areas with the lowest base flow in the Loess Plateau (Sun, 1995). Among the examined stations, $\overline{h_{\mathrm{aB}}}$ at the Huangfu station (\#41) was the minimum for both periods. In contrast, $\overline{h_{\mathrm{aB}}^{\prime}}$ at the Huangfu station (\#41) is not the smallest whether before 1970 or after 1970. Hence, a significant overestimation by the filter method is expected, leading to a much smaller $\overline{h_{\mathrm{aB}}}$ than $\overline{h_{\mathrm{aB}}^{\prime}}$ at the Huangfu station (\#41) for both periods (Fig. 4 and Table 2).
$\overline{h_{\mathrm{aB}}}$ is smaller than $\overline{h_{\mathrm{aB}}^{\prime}}$ for 13 of the 17 comparisons in Table 2 . The smaller $\overline{h_{\mathrm{aB}}}$ than $\overline{h_{\mathrm{aB}}^{\prime}}$ can be related to the fact that the filter method commonly overestimates base flow, as reported in eastern Australia (SKM and CSIRO, last accessed in October, 2014) and in southeast Australia

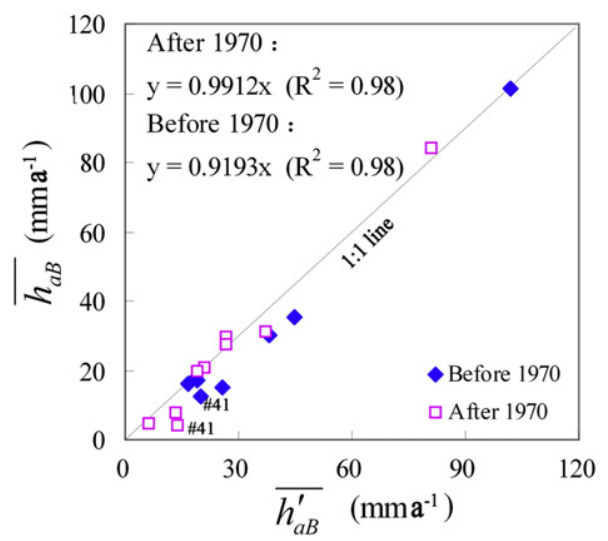

Fig. 4. Comparisons between $\overline{h_{\mathrm{aB}}}$ (the mean annual base flow estimated from the regression equation of $S S Y_{\mathrm{a}}=b h_{\mathrm{a}}+a$ ) and $\overline{h_{\mathrm{aB}}^{\prime}}$ (the mean annual base flow estimated from the Lyne and Hollick filter method). $\overline{h_{\mathrm{aB}}}=-a / b$. 

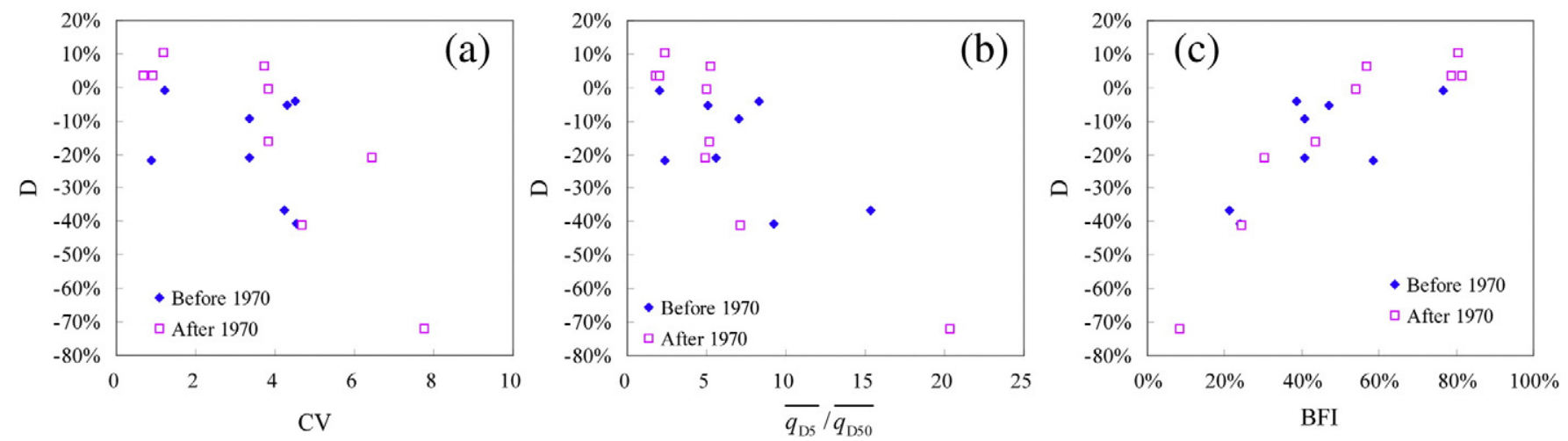

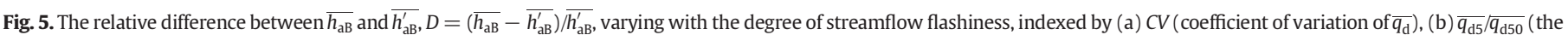
daily discharge corresponding to $5 \%$ frequency of exceedance divided by the median $\overline{q_{\mathrm{d}}}$ ), and (c) BFI (the ratio of $\overline{h_{\mathrm{aB}}}$ to the arithmetical mean of $h_{\mathrm{a}}$ ).

(Cartwright et al., 2013). This is because the filter method yields an estimation of base flow including all delayed components not just groundwater flows (Brodie et al., 2007; Nathan and McMahon, 1990). Though base flow generally dominates the delayed component, other sources, such as bank storage and interflow, also contribute to the delayed component (Cartwright et al., 2013; SKM and CSIRO, last accessed in October, 2014). In the Barwon River, southeast Australia, the Lyne and Hollick filter method significantly overestimated base flow compared to the geochemical method, especially following periods of high discharge in winter, as a result of bank return flows feeding the river for several weeks to months (Cartwright et al., 2013).

Flashy rivers, which would have more bank storage at high discharges and thus more return flows at low discharges, should be more subject to overestimated base flow than their less flashy counterparts when using the filter method. As shown in Fig. 5, a significantly smaller $\overline{h_{\mathrm{aB}}}$ than $\overline{h_{\mathrm{aB}}^{\prime}}$ always occurs at rivers with a high variation in $\overline{q_{\mathrm{d}}}$, whether the variation is indexed by the coefficient of variation (Fig. 5(a)) or the ratio of the extremely large value to the median value (Fig. 5(b)). A high $B F I$ implies a less flashy flow regime and thus, a less overestimation when using the filter method. As a result, $\overline{h_{\mathrm{aB}}}$ matches well $\overline{h_{\mathrm{aB}}^{\prime}}$ with relative differences ranging between $-20 \%$ and $10 \%$ when $B F I$ is higher than $40 \%$, and the mismatch between $\overline{h_{\mathrm{aB}}}$ and $\overline{h_{\mathrm{aB}}^{\prime}}$ dramatically increases with decreasing BFI (Fig. 5(c)). As can be perceived in Fig. 3, the Huangfuchuan River (\#41) was flashier after 1970 than before 1970. Responding to this change in hydrological regime, $\overline{h_{\mathrm{aB}}}$ is $72 \%$ smaller than $\overline{h_{\mathrm{aB}}^{\prime}}$ for the period after 1970 , a ratio much greater than that for the period before 1970 (37\%, Table 2).

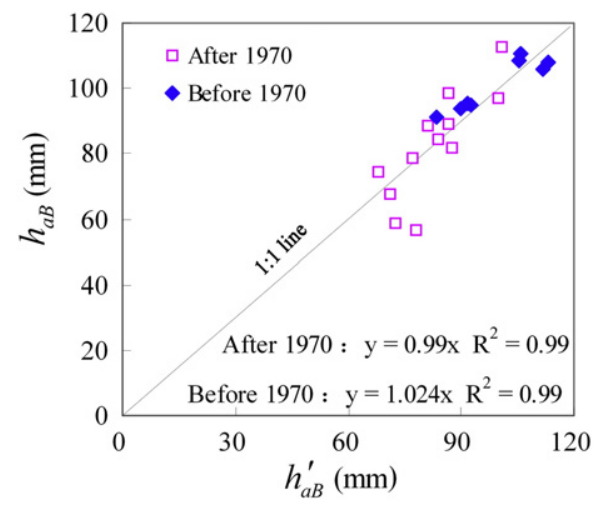

Fig. 6. Comparisons between $h_{\mathrm{aB}}$ (the annual base flow estimated from the regression equation of $S S Y_{\mathrm{m}}=b h_{\mathrm{m}}+a$ ) and $h_{\mathrm{aB}}{ }^{\prime}$ (the annual base flow estimated from the Lyne and Hollick filter method). $h_{\mathrm{aB}}=-12 a / b$. SSY $\mathrm{m}$ is not significantly correlated with $h_{\mathrm{m}}$ $(p<0.05)$ for 11 years among the examined period (1956-1989). These years were not included.
The base flow amount at other time scales can also be obtained using flow-sediment relationships observed at finer time scales. We calculated the annual base flow using the $h_{\mathrm{m}}-S S Y_{\mathrm{m}}$ relationship and the monthly base flow using the $\overline{q_{\mathrm{d}}}-\overline{S D_{\mathrm{d}}}$ relationship at the Gaojiachuan station (\#43), which has the greatest BFI among examined stations. The regression equations of $S S Y_{\mathrm{m}}=b h_{\mathrm{m}}+a$ were established for every year. The resultant value of $-a / b$ implies the mean monthly base flow in a year. Hence, $h_{\mathrm{aB}}=-12 a / b$ can be considered as an estimation of the base flow amount in that year (in $\mathrm{mm}$ ). Likewise, the value of $-a / b$ (in $\mathrm{m}^{3} \mathrm{~s}^{-1}$ ), deriving from the regression equation of $\overline{S D_{\mathrm{d}}}=b \overline{q_{\mathrm{d}}}+a$, implies the mean base flow in a month. Note that $-a / b$ has the same unit as $\overline{q_{\mathrm{d}}}$ herein. Hence, $Q_{\mathrm{mB}}=-N / 10000 \cdot a / b$, where $N$ represents the number of seconds within a month, can be considered as an estimation of the amount of base flow in that month (in $10^{4} \mathrm{~m}^{3}$ ). As shown in Figs. 6 and 7, both $h_{\mathrm{aB}}$ and $Q_{\mathrm{mB}}$ agree well with estimations from the Lyne and Hollick filter method except for cases of a poor flow-sediment relationship.

\section{Conclusions}

For the Chinese Loess Plateau, the runoff-sediment yield relationship at the watershed scale can be reasonably modeled using a linear function. The intercept of this linear relationship, corresponding to the non-erosive-flow component of streamflow, can be used to estimate base flow. We test this hypothesis using the long-term data (1950s to 1980s) of eight tributaries in the middle Yellow River. These rivers

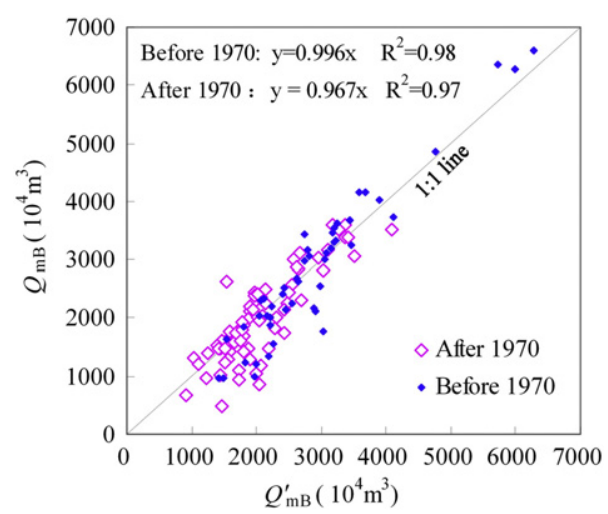

Fig. 7. Comparisons between $Q_{m B}$ (the monthly base flow estimated from the regression equation of $\overline{S D_{\mathrm{d}}}=b \overline{q_{\mathrm{d}}}+a$ ) and $Q_{\mathrm{mB}}$ ' (the monthly base flow estimated from the Lyne and Hollick filter method ). $Q_{\mathrm{mB}}=-N / 10000 \cdot a / b$, where $N$ represents the number of seconds in a month. Only flood seasons (June to September) were involved because the $\overline{S D_{\mathrm{d}}}$ $\overline{q_{\mathrm{d}}}$ relationship is generally poor for other months. Four of the 124 examined months have a less significant $\overline{S D_{\mathrm{d}}}-\overline{q_{\mathrm{d}}}$ relationship $(p<0.05)$ or a positive $a$ value. These months were not included. 
represent various land surface compositions in the middle Yellow River. The long term mean, annual and monthly base flow derived from the flow-sediment relationship all agree well with those derived from the Lyne and Hollick filter method whether the watershed management for soil conservation was implemented or not. Moreover, the Lyne and Hollick filter method, including all delayed components of streamflow not just groundwater flows into base flow, tends to overestimate base flow. The overestimation is expected to be particularly significant for flashy rivers, where bank storage provides more return flows at low discharges. Our derived base flow is essentially smaller than that derived from the filter method particularly for flashy rivers, we thus believe that our method is more accurate than the Lyne and Hollick filter method. Considering that there is no direct way to continuously measure base flow, our method is of important significance through providing validation data in assessing the performance of base flow separation methods.

The proportional model of the runoff-sediment yield relationship is applicable for regions where sediment supply is sufficiently available, such as the Walnut Gulch Experimental watershed of USA (Gao et al., 2013; Zheng et al., 2012). The proportional relationship in the Walnut Gulch Experimental watershed would also become linear with a nonzero intercept responding to the presence of base flow at the watershed scale, as has been observed in the Loess Plateau (Zheng et al., 2012). Hence, our findings are indicative of the Walnut Gulch Experimental watershed and other regions characterized by high sediment availability.

\section{Acknowledgment}

This research is funded by the National Natural Science Foundation of China (41271306 and 41271304) and the Non-Profit Industry Financial Program of MWR (201201083). The author would like to acknowledge the helpful comments made by Dr. C. Gomez and the anonymous reviewers. Thanks are also due to the Data Sharing Infrastructure of Earth System Science - Data Sharing Infrastructure of Loess Plateau (www.geodata.cn) for providing almost all of the data that are used.

\section{References}

Aksoy, H., Kurt, I., Eris, E., 2009. Filtered smoothed minima base flow separation method. J. Hydrol. 372, 94-101.

Arnold, J.G., Muttiah, R.S., Srinivasan, R., Allen, P.M., 2000. Regional estimation of base flow and groundwater recharge in the Upper Mississippi river basin. J. Hydrol. 227 21-40.

Brodie, R., Sundaram, B., Tottenham, R., Hostetler, S., Ransley, T., 2007. An Overview of Tools for Assessing Groundwater-Surface Water Connectivity. Bureau of Rural Sciences, Canberra (133 pp.).

Cartwright, I., Gilfedder, B., Hofmann, H., 2013. Contrasts between chemical and physical estimates of base flow help discern multiple sources of water contributing to rivers. Hydrol. Earth Syst. Sci. 10, 5943-5974.
Chapman, T., 1999. A comparison of algorithms for stream flow recession and base flow separation. Hydrol. Process. 13, 701-714.

Dou, L., Huang, M.B., 2010. Applied study of base flow separation methods in watersheds of loess plateau. Bull. Soil Water Conserv. 30 (3), 107-112 (in Chinese).

Fang, N.F., Shi, Z.H., Li, L., Jiang, C., 2011. Rainfall, runoff, and suspended sediment delivery relationships in a small agricultural watershed of the Three Gorges area, China. Geomorphology 135, 158-166.

Furey, P.R., Gupta, V.K., 2001. A physically based filter for separating base flow from streamflow time series. Water Resour. Res. 37, 2709-2722.

Gao, P., Nearing, M.A., Commons, M., 2013. Suspended sediment transport at the instantaneous and event time scales in semiarid watersheds of southeastern Arizona, USA. Water Resour. Res. 49, 6857-6870. http://dx.doi.org/10.1002/wrcr.20549.

Gonzales, A.L., Nonner, J., Heijkers, J., Uhlenbrook, S., 2009. Comparison of different base flow separation methods in a lowland catchment. Hydrol. Earth Syst. Sci. 13 2055-2068.

Hall, F.R., 1968. Base-flow recessions - a review. Water Resour. Res. 4 (5), 973-983.

Huyck, A.A.O., Pauwels, V.R.N., Verhoest, N.E.C., 2005. A base flow separation algorithm based on the linearized Boussinesq equation for complex hillslopes. Water Resour. Res. 41, W08415. http://dx.doi.org/10.1029/2004WR003789.

Jiao, E.Z., 1993. The changing trend of fluvial sediment yield in the Huangfuchuan watershed. In: Wang, G., Fan, Z. (Eds.), Studies on Changes of Fluvial Sediment Processes in the Yellow River Basin vol. 1. Huanghe Hydraul. Press, Zhengzhou, China, p. 291 (in Chinese).

Liu, B.Y., Nearing, M.A., Risse, L.M., 1994. Slope gradient effects on soil loss for steep slopes. Trans. ASAE 37 (6), 1835-1840.

Nathan, R.J., McMahon, T.A., 1990. Evaluation of automated techniques for base flow and recession analysis. Water Resour. Res. 26, 1465-1473.

Santhi, C., Allen, P.W., Muttiah, R.S., Arnold, J.G., Tuppad, P., 2007. Regional estimation of base flow for the conterminous United States by hydrologic landscape regions. J. Hydrol. 351, 139-153.

Sedimentation Commission of Chinese Society of Hydraulic Engineering, 1992. Handbook of Sedimentation. Publishing House for Environmental Sciences, Beijing (in Chinese).

SKM (Sinclair Knight Merz), CSIRO (the Commonwealth Scientific and Industrial Research Organisation), last accessed in October, 2014. Approaches for the assessment of surface water-groundwater interaction. Available from the Department of Sustainability, Environment, Water, Population and Communities, Australian (http://www. environment.gov.au/system/files/pages/f4c0c901-66bc-46ba-94cb-056dfb54b69d/ files/approaches-assessment-surface-water.pdf).

Spongber, M.E., 2000. Spectral analysis of base flow separation with digital filters. Water Resour. Res. 36, 745-752.

Sun, S., 1995. Local Chronicles of Shaanxi Province (Volume V): Chronicles of Loess Plateau. Shaanxi People's Press, Xi'an (in Chinese).

Tallaksen, L.M., 1995. A review of base flow recession analysis. J. Hydrol. 165, 149-370.

Yan, Y.S., 1984. An Introduction to Hydrometry. Water Conservancy and Electric Power Press, Beijing (in Chinese).

Yan, B., Fang, N.F., Zhang, P.C., Shi, Z.H., 2013. Impacts of land use change on watershed streamflow and sediment yield: an assessment using hydrologic modelling and partial least squares regression. J. Hydrol. 484, 26-37.

Zheng, M.G., Cai, Q.G., Cheng, Q.J., 2008. Modelling the runoff-sediment yield relationship using a proportional function in hilly areas of the Loess Plateau, North China. Geomorphology 93, 288-301.

Zheng, M.G., Qin, F., Sun, L.Y., Qi, D.L., Cai, Q.G., 2011. Spatial scale effects on sediment concentration in runoff during flood events for hilly areas of the Loess Plateau, China Earth Surf. Process. Landf. 36, 1499-1509.

Zheng, M.G., Yang, J.S., Qi, D.L., Sun, L.Y., Cai, Q.G., 2012. Flow-sediment relationship as functions of spatial and temporal scales in hilly areas of the Chinese Loess Plateau. Catena 98, 29-40.

Zheng, M.G., Qin, F., Yan, J.S., Cai, Q.G., 2013. The spatio-temporal invariability of sediment concentration and the flow-sediment relationship for hilly areas of the Chinese Loess Plateau. Catena 109, 164-176. 